\title{
СОЦИОМЕТРИЧЕСКАЯ ЭКСПЕРТНАЯ МЕТОДИКА Р ЦЯВЛЕНИЯ СОТРУДНИКОВ ОРГАНОВ ВНУТРЕННИХ ДЕЛ, СКЛОННЫХ К ИСКАЖЕНИЮ СЛУЖЕБНОЙ ИНФОРМАЦИИ
}

В статье представлены материалы по разработке сочиометрической экспертной методики выявления сотрудников органов внутренних дел, склонных к искажению служебной информации при осуществлении ими профессиональной деятельности. Представлен опросник, состоящий из семи вопросов, три из которых отражают отношение очениваемых сотрудников к искажению служебной информации; три вопроса оченивают действия

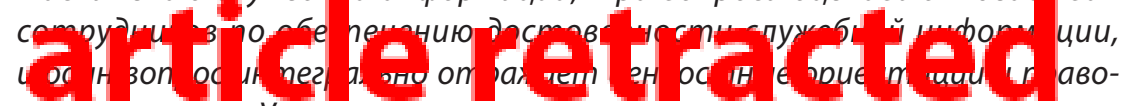
вые установки. Установлены критерии оценки склонности к искажению информации, подтвержденные показателями поведенческих проявлений, а также дисциплинарной практикой, определены направления исследований по определению профессионально-психологических механизмов изучаемого феномена.

В качестве экспертов выступили 438 сотрудников 14 территориальных

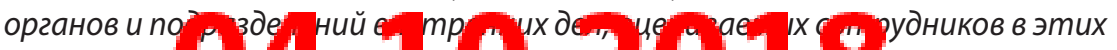

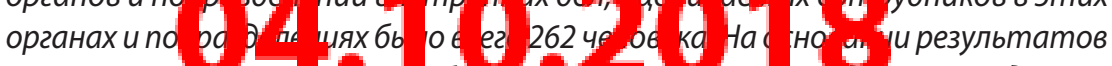
статистического инализа обследуемин оборка ситруиников разделена на три группы относительно интегрального показателя, определяющего выраженность такого психологического качества, как склонность к искажению служебной информации: высокий уровень интегрального показателя (ИП $\geq 0,826)$, низкий уровень интегрального показателя (ИП $\leq 0,537)$ и промежуточная группа, в которую вошли сотрудники с уровнем интегрального показателя от 0,538 до 0,827. Дальнейшее исследование проводилось с двумя полярными группами и включало в себя: изучение особенностей их служебного поведения, психологических характеристик, состояния дисциплинарной практики, психодиагностическое обследование ченностносмысловой сферы и др. 
В заключении определены направления для изучения личностных особенностей сотрудников ОВД, склонных к искажению служебной информации.

Ключевые слова: искажение информачии, экспертная методика, социометрическая методика, психодиагностика, мониторинг, полярные группы, сотрудник ОВД, юридическая психология.

Профессиональная деятлп : оость сотрудников органов внутренних дел (ОВД) сложна и многообразна, связана с непрерывным потоком информации, которая поступает в различных формах и видах (звуковой, текстовой, графической, числовой). В дальнейшем она систематизируется, обобщается, передается и хранится. Сотрудникам ОВД для осуществления служебной де-

с тем любая передаваемая информация может подвергаться искажению, изменению смысла и содержания, независимо от того, каким образом она будет распространяться.

Актуальность исследования проблемы искажения информации подтверждается данными, свидетельствующими о том, что значительное число сотрудников ОВД к дисциплинарной и уголовной ответственности чаще

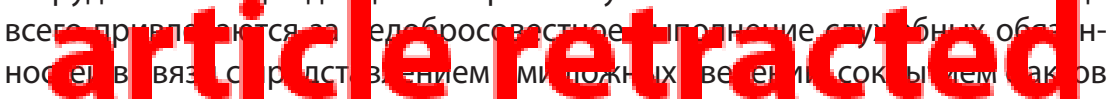
обращения к ним в целях склонения к коррупционному правонарушению, размещением недостоверных сведений в отчетных документах для улучшения показателей оперативно-служебной деятельности и т. д. $[1,3,5,7]$. Анализ данных надзорных органов за деятельностью правоохранительных органов, в частности, актов прокурорского реагирования по устранению нарушений федерального законодательства по линии МВД России, показы-

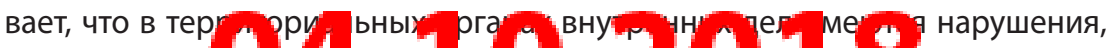

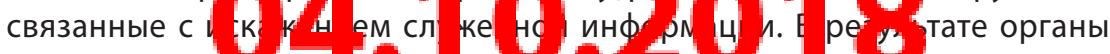
прокуратуры РоссийскойФедерации треоуют привлеченил виновных лиц к дисциплинарной ответственности.

Изучение отечественных специальных публикаций показывает, что являются недостаточно изученными вопросы искажения сотрудниками ОВД служебной информации, детерминирующие его профессиональные и психологические факторы, условия и причины, связанные с организацией службы, оценкой результатов деятельности, влияющих на уровень объективности сведений, собираемых и используемых в процессе служебной деятельности сотрудниками ОВД $[4,6,9,11,14]$. В необходимости изучения профессиональных и психологических детерминант в фактах искажения сотрудниками ОВД служебной информации, их профилактики в интересах 
повышения уровня ее достоверности для принятия на их базе адекватных управленческих решений, способствующих повышению эффективности функционирования системы МВД России, и заключается актуальность настоящей работы.

Цель исследования представляет поиск подходов к разработке экспертной социометрической методики выявления сотрудников органов внутренних дел, склоннц:.' ' искажению служебной информации.

В этой связи заметим, что в органах внутренних дел для психологического изучения личности сотрудников используются различные психодиагностические методики, оценивающие степень выраженности тех или иных психологических качеств. Однако они не позволяют выявлять лиц, склонных

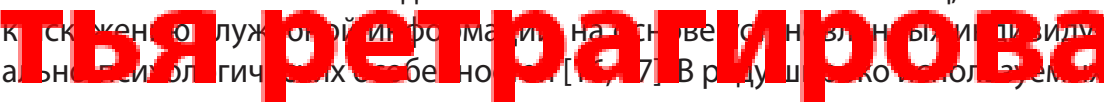
психодиагностических методик во многих случаях применяется метод экспертных оценок, имеющий самостоятельную диагностическую ценность. Основным преимуществом этого метода является возможность создания интегративного психологического «портрета» испытуемого, описания его личностных особенностей как системы взаимосвязанных, взаимозависимых и компенсирующих друг друга качеств. Объективность собираемой инфор-

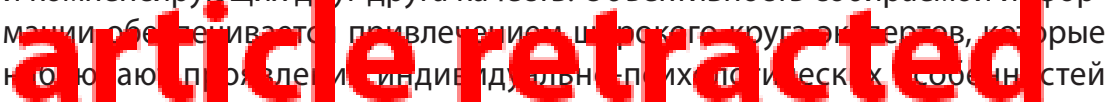
человека на протяжении длительного времени, при непосредственном общении в различных типах ситуаций, возникающих в процессе его профессиональной деятельности.

Особое место в этом ряду экспертных методик, позволяющих выявить неформальную структуру статусов в коллективе по заданным основаниям, к примеру, склонности к искажению служебной информации, занимает

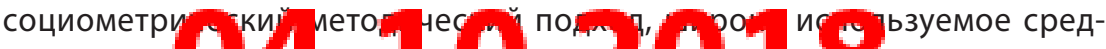
ство измер чи а иальн пс хо огиче kv $Г$ каз те су членов группы (И. А. Андрееьа, А. ๖. Яетровскии и д... фслед за этим остает вопрос об экспертных социометрических методах выявления сотрудников органов внутренних дел, определения их отличительных характеристик, при наличии которых можно отнести их к категории лиц, проявляющих склонность к искажению служебной информации [2, 4, 10, 15].

Представляется, что целям настоящего исследования может соответствовать модифицированный вариант социометрической процедуры, реализованный в программе социально-психологических исследований «Мониторинг», позволяющей определять сотрудников ОВД, обладающих негативным статусом в коллективе по критериям, отражающим деятельностный характер их взаимоотношений (М. И. Марьин, А. А. Бочкова и др.) $[6,8]$. 
Автоматизированная программа создана в среде FoxPro 2.5 для Windows и включает несколько баз данных, процедуры обработки и графической интерпретации результатов тестирования.

Методическая часть программы «Мониторинг» представляет собой опросник, в котором каждый включенный в список сотрудник оценивается по семи вопросам, три из которых отражают отношение оцениваемых сотрудников к искажению служебной и: фалммации; три вопроса оценивают действия сотрудников по обеспечению достоверности служебной информации и один вопрос интегрально отражает ценностные ориентации и правовые установки. Сотруднику предлагается следующий перечень вопросов:

1. Всегда ли стремится избежать искажения служебной информации?

3. Всегда ли стремится передавать только правдивую информацию?

4. Является ли служебная необходимость оправданием искажения информации?

5. Влияет ли личная заинтересованность на искажение информации?

6. Всегда ли стремится отстаивать достоверность служебной информации?

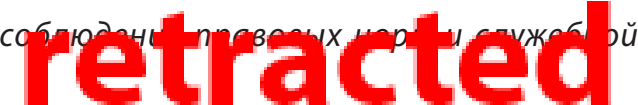

В исследовании в качестве экспертов (оценщиков) выступали 438 сотрудников 14 территориальных органов и подразделений внутренних дел, оцениваемых сотрудников в этих органах и подразделениях было всего 262 человека. В результате проведенного исследования для каждого оцениваемого сотрудника были получены интегральные показатели (ИП), характеризующие его по признакам отношения к искажению служебной информации, по признакам действ 70 , еспе ию а стов о ос илуеб у информации,

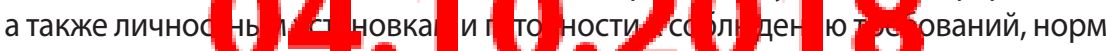
и правил служечного поведения вповседпсонои служебноидеятельности.

Кривая распределения переменных по параметру интегральной оценки представлена на рисунке 1. Полученные переменные измеряются в шкале отношений, и их распределение близко к нормальному, а числовые значения этих переменных лежат в пределах от 0 до 1, со средним значением 0,682 и стандартным отклонением, равным 0,145.

На основании результатов статистического анализа, обследованная выборка сотрудников была разделена на три группы относительно интегрального показателя, определяющего выраженность такого психологического качества, как склонность к искажению служебной информации. Высокий уровень интегрального показателя (ИП $\geq 0,826)$ характеризует сотрудника 
как человека, не склонного к искажению служебной информации, соблюдающего правовые нормы в повседневной служебной деятельности; низкий уровень интегрального показателя (ИП $\leq 0,537)$ характеризует сотрудника как человека, склонного к искажению служебной информации, допускающего возможность нарушения правовых норм и требований нормативных правовых документов; в промежуточную группу вошли сотрудники с уровнем интегрального показател п 0,538 до 0,827.

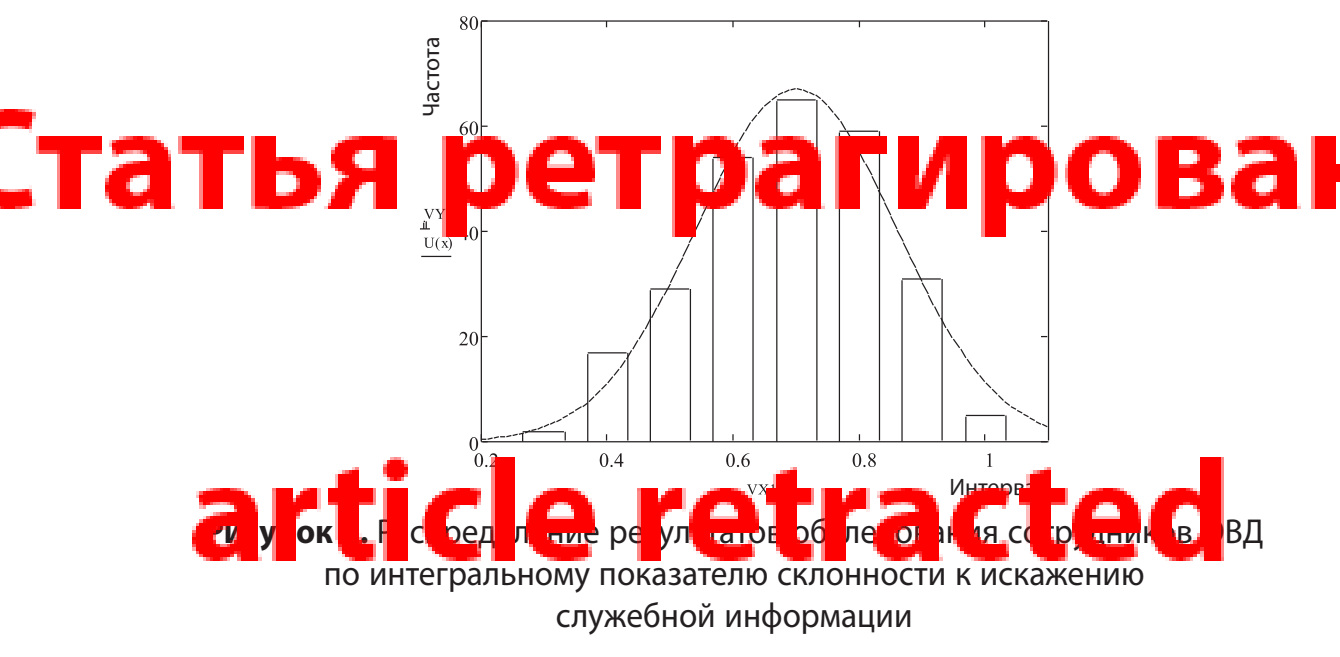

В число сотрудников с низким уровнем интегрального показателя вошли 44 человека (16 \%), а в число лиц с высоким уровнем - 48 человек (18\%) (рисунок 2).

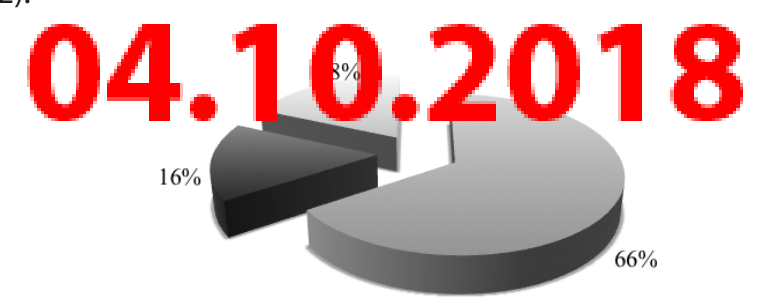

Рисунок 2. Распределение сотрудников по интегральному показателю склонности к искажению служебной информации

Сотрудники, составившие указанные полярные группы, подверглись углубленному изучению особенностей их служебного поведения, психологических характеристик, состояния дисциплинарной практики, характера 
дисциплинарных правонарушений (поощрения и наказания), включенности в группу повышенного психолого-педагогического внимания, частоты случаев обращения к психологу подразделения за психологической консультацией и психологической помощью.

Кроме того, была изучена доступная служебная документация личного состава, проведено психодиагностическое обследование ценностно-смысловой сферы сотрудников пллярных групп. Ценностно-смысловая сфера, как центральное образование личности, задает направленность жизнедеятельности человека и определяет соотношение «человек-мир». Ценность в сознании человека существует в представлениях о себе, в самоощущении и самоотношении, т. е. выражается в когнитивных, эмоциональных и оце-

cacupar

методика ценностных ориентаций М.Рокича, которая состояла из 18 терминов, включавших в себя два класса ценностей: терминальные и инструментальные [4]. Данная методика способна определить жизненную позицию сотрудников двух сравниваемых групп, уровень их вовлеченности в сферу профессиональной деятельности, семейно-бытовую и досуговую активность. Сравнительная характеристика двух обследованных групп сотрудников

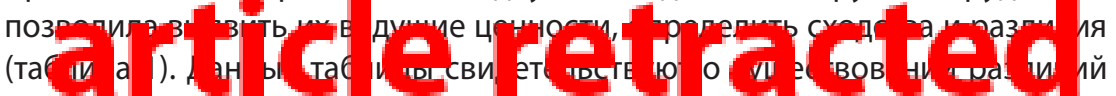
между группами сравнения в показателях ценностно-смысловой сферы, структуре ценностей и их приоритетности в служебной деятельности.

В группе сотрудников, склонных к искажению служебной информации, приоритетными ценностями, отличающими их от сотрудников, не склонных к искажению служебной информации, являются: карьерный рост, совершенствование личности, материально обеспеченная жизнь. В группе сотрудников, не склонных қ а қаж ию с кеб й инфо ма ли, ис уриоритетных ценностей отн ся блюде ие бе ован з выражения взглгдов, бездвоиныхстандартов.

Таблица 1.

Ранжирование исследованных ценностей в группах сравнения

\begin{tabular}{|c|c|c|c|}
\hline Ранг & Гpynna 1 & Ранг & Гpynna 2 \\
\hline 1 & $\begin{array}{c}\text { Физическое и психическое } \\
\text { здоровье }\end{array}$ & 1 & $\begin{array}{c}\text { Физическое и психическое } \\
\text { здоровье }\end{array}$ \\
\hline 2 & Материально обеспеченная жизнь & 2 & Благополучная семейная жизнь \\
\hline 3 & $\begin{array}{c}\text { Благополучная } \\
\text { семейная жизнь }\end{array}$ & 3 & $\begin{array}{c}\text { Соблюдение требований закона, } \\
\text { приказов }\end{array}$ \\
\hline 4 & $\begin{array}{c}\text { Карьерный рост, совершенствова- } \\
\text { ние личности }\end{array}$ & 4 & $\begin{array}{c}\text { Искренность выражения взглядов, } \\
\text { без двойных стандартов }\end{array}$ \\
\hline
\end{tabular}


Выявленные различия в ценностно-смысловой сфере сотрудников двух групп сравнения говорят о детерминированности феномена искажения служебной информации внутренними базовыми ценностными факторами, затрагивающими его глубинные психологические механизмы, определяющие спектр направленности личности.

На рисунке 3 приведен анализ данных относительно особенностей служебного поведения сотр;.'.'^ков групп сравнения. Они говорят о том, что полученные интегральные показатели склонности к искажению служебной информации у обследованных сотрудников нашли свое подтверждение в объективных показателях их профессиональной деятельности, в частности, в дисциплинарной практике, которая была использована в качестве внешнего

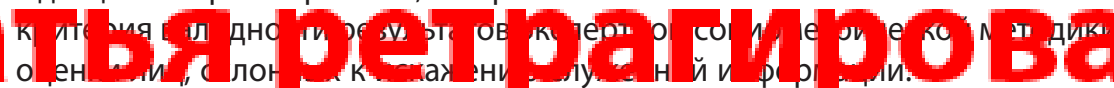

Анализ статистических данных по привлечениюсотрудников к дисциплинарной ответственности показал, что у лиц с высоким уровнем ИП дисциплинарных взысканий (наказаний) более чем в два раза меньше, чем у сотрудников с низким уровнем ИП, а число поощрений на 20 \% больше, чем у сотрудников противоположной группы. Аналогичным образом сотрудники полярных групп распределились и по частоте обращений запси-

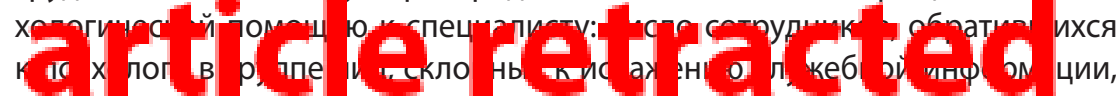
в два раза больше, чем в альтернативной группе.

Еруппа $1=$ Группа 2

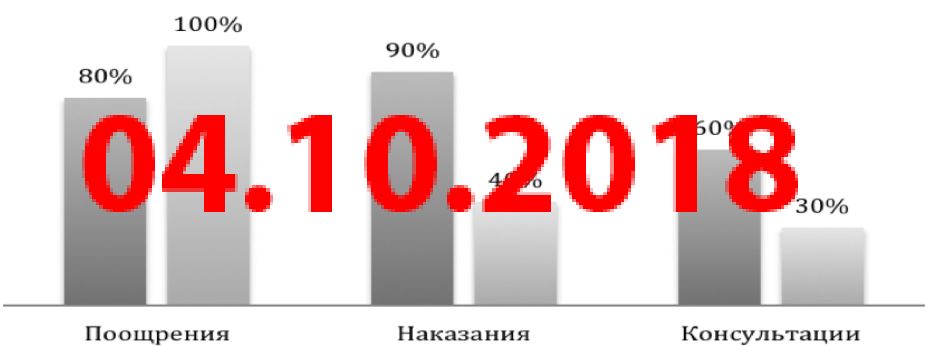

Рисунок 3. Соотношение показателей дисциплинарной практики и консультаций у психолога среди сотрудников ОВД в группах сравнения: склонных (группа 1) и не склонных (группа 2) к искажению служебной информации

Значительный интерес представляют данные рисунков 4 и 5, в которых показано, что за один и тот же временной интервал число случаев наказания 
Практическое применение предлагаемой экспертной социометрической методики будет способствовать совершенствованию системы внутреннего контроля среди действующих сотрудников органов и подразделений внутренних дел, решению вопросов методического обеспечения диагностики сотрудников, нуждающихся в коррекции, для включения их в группы психолого-педагогического внимания. Это расширит возможности своевременной психодиагностики и эффс:'т: : среди сотрудников органов внутренних дел. Данный методический подход может быть использован при формировании резерва кадров на выдвижение на вышестоящие должности, для определения общей направленности ценностно-смысловой сферы как отдельного сотрудника, так и служебного т'вя" ретрагирова Литература

1. Ажимова О. А., Марьин М. И., Петров В. Е. Современные технологии организации психологической работы в органах внутренних дел: методическое пособие. - М., 2005. - 277 с.

2. Василюк Ф.Е. Уровни построения переживания и методы психологической науки // Вопросы психологии. - 1988. - № 5. - С. 27-37.

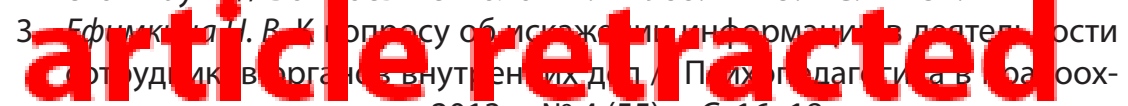
ранительных органах. - 2013. - № 4 (55). - С. 16-18.

4. Знаков В. В. Неправда, ложь и обман как проблемы психологии понимания // Вопросы психологии. - 1993. - № 2. - С. 9-17.

5. Иванова Е. М. Психология профессиональной деятельности. - М., 2011. - С. 58-59.

6. Марьин М. И., Бочкова А. А. Психологические особенности сотрудников ОВД, скл а ых, прот оп номуш ве лир П иладная юридическая г и) , я. -2 4. N 3.-C,753

7. Марьин М.И., Ббчкөва Л. А., сафропио А. д., Каспероочч Ю. Г., Ефимкина Н. В. Психологическое обеспечение профилактики преступлений коррупционной направленности у сотрудников органов внутренних дел: методические рекомендации. - М.: Изд-во Академии управления МВД России, 2014. - 44 с.

8. Марьин М. И., Котенёв И. О., Киселёва Л. Е. Методика экспертных оценок эффективности адаптации к управленческой деятельности выпускников Академии управления МВД России: учеб.-практ. пособие. - М.: Изд-во Академии управления МВД России, 2012. - 96 с.

9. Пономарёва М. А., Юхновец Т. И. Психодиагностика личности: пособие для студентов вузов. - Минск, 2008. 


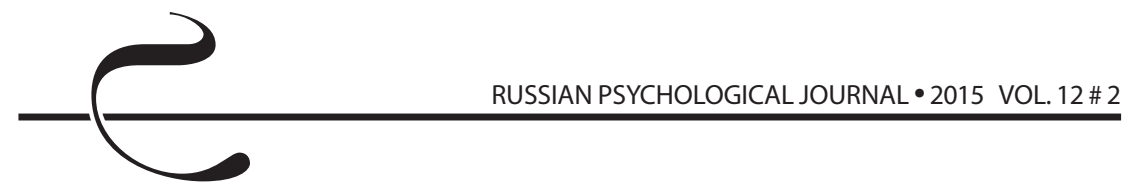

10. Психологические тесты / Под ред. А. А. Карелина. - Т. 1. - М., 2000. C. 25-29.

11. Тарасов А. Н. Психология лжи. - М.: Книжный мир, 2005. - 327 с.

12. Удалова Е. А. Искажения соционического типа. Быть или казаться. - М., 2009. - 191 c.

13. Ценностные основания психологической науки и психология ценностей / Отв. ред. В. В. 2.’^ов, Г. В. Залевский. - М.: Изд-во Института психологии РАН, 2008. - С. 13.

14. Щербатых Ю. В. Психология лжи и обмана. - Ростов н/Д: Феникс, 2011. - 284 c.

15. Экман П. Психология лжи [Telling Lies: Clues to Deceit in the Marketplace,

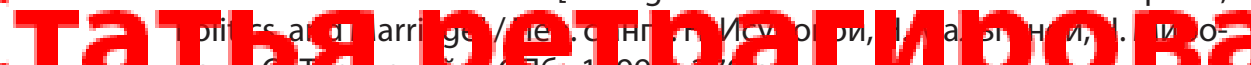

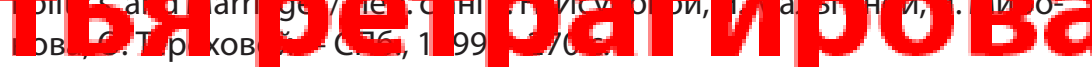

16. Экстремальная психология в особых условиях деятельности: монография / Под науч. ред. Б. Г. Бовина. - М., 2015. - 514 с.

17. Weinrich H. Linguistik der Luge. - Aufl. - Munchen: Beck, 2000. - 90 p.

\section{article retracted}

\subsection{0 .2018}

